\title{
Classifying forest species using hyperspectral data in Balah forest reserve, Kelantan, Peninsular Malaysia
}

\begin{abstract}
This study attempts to classify forest species using hyperspectral data for supporting resources management. The primary dataset used was AISA sensor. The sensor was mounted onboard the NOMAD GAF-27 aircraft at 2,000 m altitude creating a $2 \mathrm{~m}$ spatial resolution on the ground. Pre-processing was carried out with CALIGEO software, which automatically corrects for both geometric and radiometric distortions of the raw image data. The radiance data set was then converted to at-sensor reflectance derived from the FODIS sensor. Spectral Angle Mapper (SAM) technique was used for image classification. The spectra libraries for tree species were established after confirming the appropriate match between field spectra and pixel spectra. Results showed that the highest spectral signature in NIR range were Kembang Semangkok (Scaphium macropodum), followed by Meranti Sarang Punai (Shorea parvifolia) and Chengal (Neobalanocarpus hemii). Meanwhile, the lowest spectral response were Kasai (Pometia pinnata), Kelat (Eugenia spp.) and Merawan (Hopea beccariana), respectively. The overall accuracy obtained was 79\%. Although the accuracy of SAM techniques is below the expectation level, SAM classifier was able to classify tropical tree species. In future it is believe that the most effective way of ground data collection is to use the ground object that has the strongest response to sensor for more significant tree signatures.
\end{abstract}

Keyword: Classify tree species; Hyperspectral; Spectral angle mapper; Spectral signature; Tropical forest; Accuracy assessment 